\title{
JUURNAL.RU
}

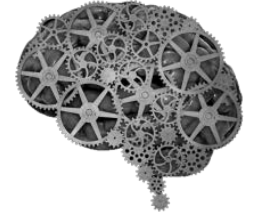

COMPANY GROUP "INTELLEKT"

\author{
Зройчиков Н.А., Каверин А.А. \\ ОАО "Энергетический институт им. Г.М. Кржижановского" \\ ФГБОУ ВО "Наииональный исследовательский университет "МЭИ" \\ Москва, Россия
}

doi: 10.18411/lj2016-6-1-10

\section{Исследование схемы сжигания экибастузского угля в топке котла с нижним дутьем}

Сжигание твердого топлива на отечественных ТЭС сопряжено с рядом трудностей: повышенный недожог топлива, проблемы с воспламенением низкосортных и низкореакционных сортов углей, повышенные выбросы оксидов азота, низкий регулировочный диапазон, шлакование экранных поверхностей и т.д.

Котельное оборудование на большинстве ТЭС России выработало свой ресурс и отличается значительным физическим износом. Все вышеуказанное неизбежно ведет к необходимости модернизации или замены котельных установок, следовательно, задача повышения эффективности сжигания твердого топлива вновь становится актуальной.

Одним из перспективных направлений совершенствования котельной техники является организация воздушного дутья в нижней части топочной камеры. Воздушные струи, выходящие из сопл нижнего дутья, создают «подпорку» для крупных частиц, проваливающихся в шлаковый комод. В связи с этим снижаются потери тепла с механическим недожогом провала и шлака q4пр+шл, факел вытягивается по высоте топки (снижая его максимальную температуру), экраны холодной воронки воспринимают больше теплоты 
(повышается коэффициент тепловой эффективности топки), снижаются выбросы оксидов азота. Появляется возможность сжигания топлива угрубленного помола.

\section{Описание исследования}

Целью настоящей работы являлось изучение влияния конструктивных и режимных параметров на показатели работы топки котла с нижним дутьем. Объект исследования - котел П-57 Подольского машиностроительного завода, [1]. Котел предназначен для работы на высокозольных экибастузских углях (ЭУ) в блоке с турбиной мощностью 500 МВт. Котел прямоточный, сверхкритического давления, с промежуточным перегревом, однокорпусный, Тобразной компоновки, с уравновешенной тягой, с твердым шлакоудалением. Система пылеприготовления с молотковыми мельницами и прямым вдуванием топлива.

Котел отличается высокой теплонапряженностью (до 6,5 MBт/м2), что приводит к повышенной температуре в ядре факела и, как следствие, к повышенным выбросам оксидов азота. Кроме того, существует опасность шлакования топочных экранов из-за высокой температуры газов у стен топки. Целью исследования является необходимость снижения максимальной температуры факела, устойчивого воспламенение топлива и обеспечения нормативных потерь тепла с механическим недожогом q4, [2].

В основу исследований положена схема организации сжигания топлива с прямоточными горелками и соплами. Схему характеризует встречно-смещенное расположение горелок и сопл, ступенчатый подвод воздуха с добавлением сопл нижнего дутья на стенах шлакового комода. Полное количество горелок сохраняется - 24 шт. Исследовались 2 варианта схемы, представленные на рис. 1.

В первом варианте (№1, рис. 1а) горелки выполнены в виде четырех труб ø377x8 мм, расположенных одна над другой. Такое исполнение значительно повышает периметр эжекции топочных газов к корню горелочных струй и увеличивает скорость воспламенения топлива, [3]. однако струи теряют 
дальнобойность, при этом сопла нижнего дутья расположены по всему фронту котла в шахматном порядке по 30 шт. на каждой стене шлакового комода, Во втором варианте (№2 рис. 1б) горелки выполнены в виде трубы ø720х8 мм с рассекателем по центру, под каждой горелкой первого яруса располагается одно сопло нижнего дутья, т. е. по шесть на каждой стене.

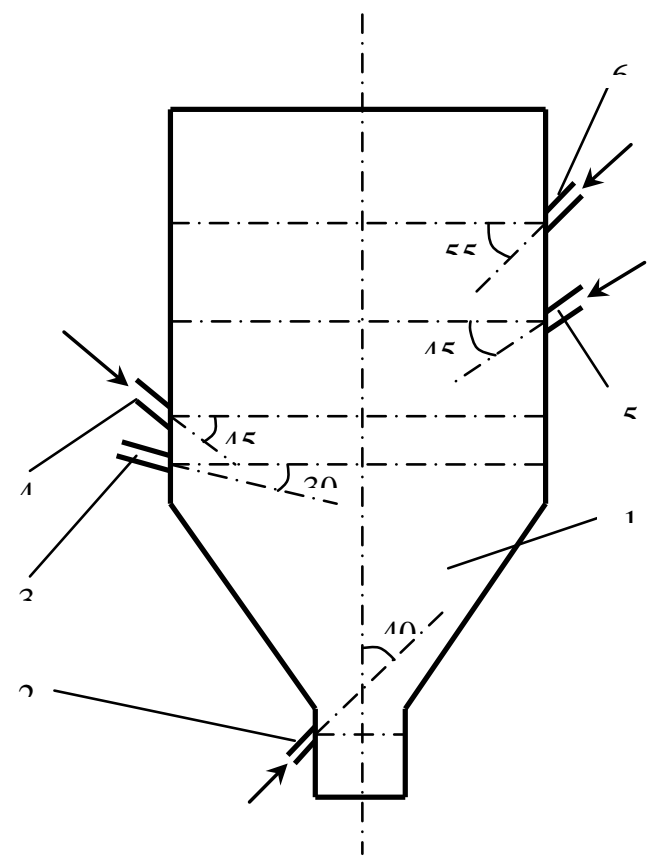

a)

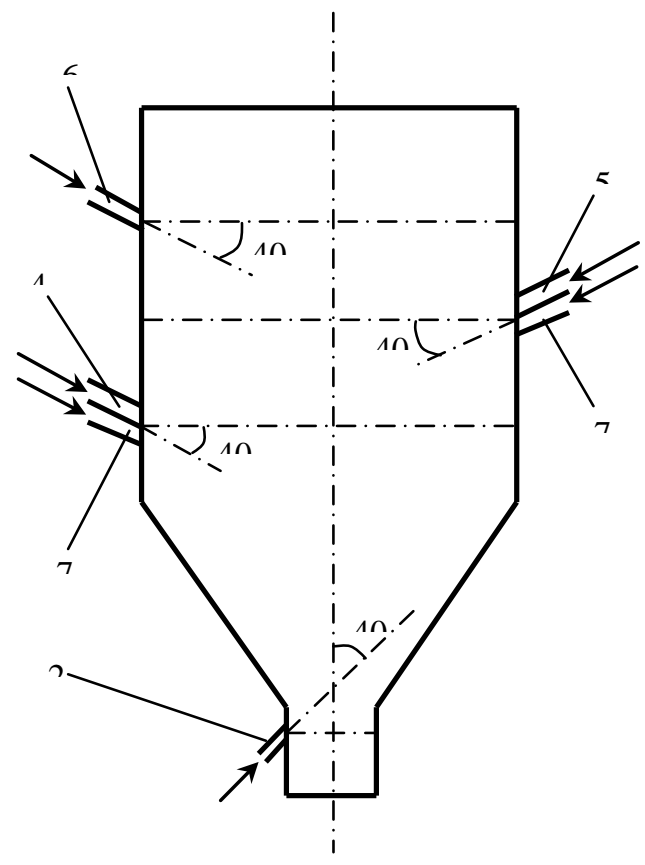

б)

Рисунок - 1. Схема сжигания топлива с нижним дутьем. а) - схема №1; б) - схема №2;

1 - топка; 2 - сопло нижнего дутья; 3 - мазутная горелка; 4 - пылеугольная горелка 1-го яруса; 5 - пылеугольная горелка 2-го яруса; 6 - сопла третичного воздуха; 7 - сопла вторичного воздуха.

Исследование проводилось методом численного моделирования вариантов в программном комплексе Ansys Fluent, [4].

В основу расчетной модели принят номинальный режим работы топки, при сжигании экибастузского угля марки $\mathrm{CC}$, работе восьми мельниц, суммарном остатке на сите R90=15\% и коэффициенте полидисперсности $\mathrm{n}=0,9$. Доля воздуха в аэросмеси определялась на основании теплового расчета пылесистемы и составила $\alpha$ гор $=0,285$, что соответствует паспортной температуре аэросмеси равной $100^{\circ} \mathrm{C}$. Подача воздуха в остальные каналы рассчитывалась пропорционально их выходным сечениям. 


\section{Результаты расчетов вариантов:}

1. Схема №1 при доле воздуха в сопла нижнего дутья $\alpha н . д=0,57$ и $\alpha н$.д = 0,35. В первом случае величина механического недожога составила q4 = $1,9 \%$, температура на выходе из топки $9^{\prime \prime} \mathrm{T}=1477^{\circ} \mathrm{C}$, во втором случае q4 $=1,6 \%, \vartheta^{\prime \prime}=1344^{\circ} \mathrm{C}$. Наибольший недожог приходится на горелки второго яруса (более 85\%) из-за нехватки кислорода и забалластированности воздуха продуктами сгорания частиц топлива из первого яруса.

2. Схема №1 с увеличенной долей первичного воздуха $\alpha$ гор $=0,45$ и доле воздуха в сопла нижнего дутья $\alpha$.д $=0,5$. Величина потерь с мехнедожогом снизилась до q4 $=0,4 \%$, при этом температура на выходе из топки составила: $9^{\prime \prime} т=1338^{\circ} \mathrm{C}$. Основной проблемой схемы №1 является восходящий поток воздуха из сопл нижнего дутья, который отжимает более слабые горелочные струи к стенам топки. В результате возникает опасность шлакования экранов топки и теряется эффект от встречно-смещенного расположения горелок.

3. Схема №2 с долей первичного воздуха в горелки $\alpha г о р=0,285$ и $\alpha$ гор = 0,35 и долях воздуха в сопла нижнего дутья $\alpha н . д=0,056$ и $\alpha$ н.д $=0,091$ соответственно. Аэродинамика становится более устойчивой, однако потери с мехнедожогом возрастают до q4 $=3,8 \%$ и q4 $=2,8 \%$ соответственно, а $\vartheta^{\prime \prime} \mathrm{T}=1298^{\circ} \mathrm{C}$ и $\vartheta^{\prime \prime} \mathrm{T}=1294^{\circ} \mathrm{C}$. Температура газов на выходе из топки заметно снижается в сравнении с первой схемой, а активная зона горения располагается в нижней части топки, что приводит к повышенным значениям температуры в ядре факела. Струи соседних горелок не могут активно взаимодействовать из-за стесненной компоновки горелок.

4. Схема №2 с уменьшением количества горелок до 16 -ти (по 4 горелки на фронтовой и задней стенках одного яруса). Количество сопл нижнего дутья и третичного воздуха пропорционально уменьшается. При этом $\alpha$ гор $=0,285, \alpha н . д=0,082, \quad q 4=1,2 \%, \vartheta^{\prime \prime}=1172^{\circ} \mathrm{C}$. Струи соседних горелок глубоко проникают в топку и активно взаимодействуют друг с другом, что положительно сказывается на воспламенении и горении топлива. Однако ядро факела сосредоточено в небольшом объеме топки, 
что приводит к повышению температуры в ядре факела, с опасными последствиями повышенного

шлакования экранов и увеличению выбросов оксидов азота.

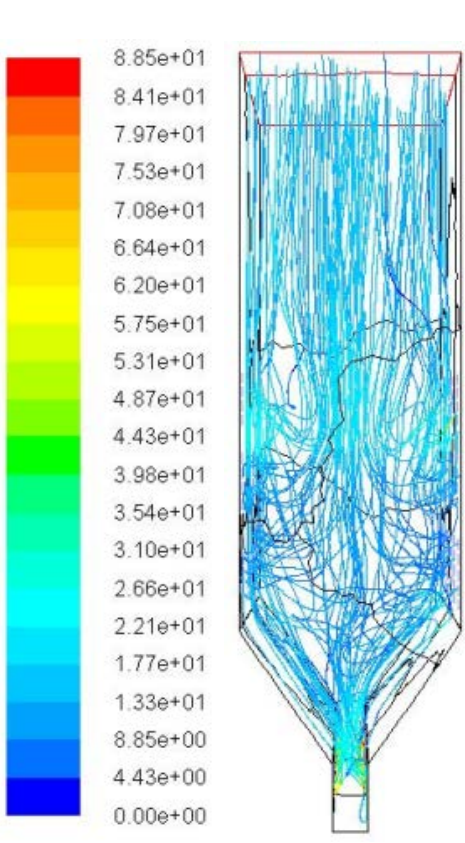

a)

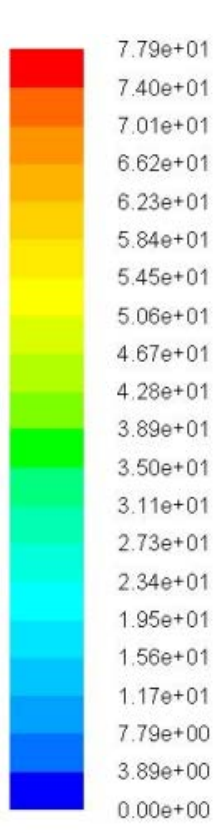

б)
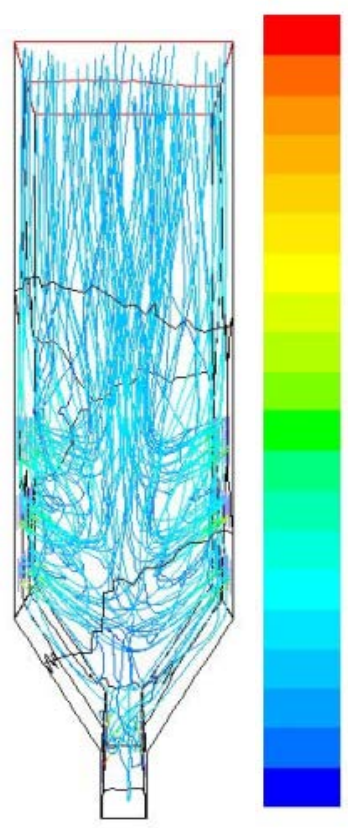

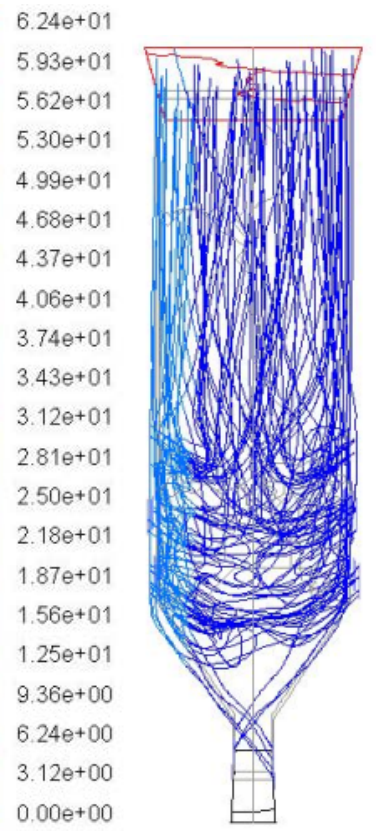

B)

Рисунок - 2. Линии тока газов, м/с a) схема №1 $\alpha$ н.д = 0,57; б) схема №2, 24 горелки; в) схема №2, 16 горелок
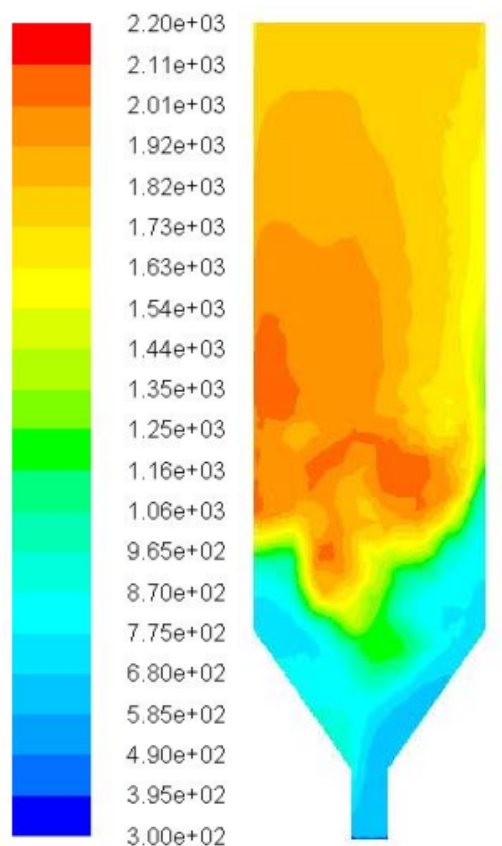

a)
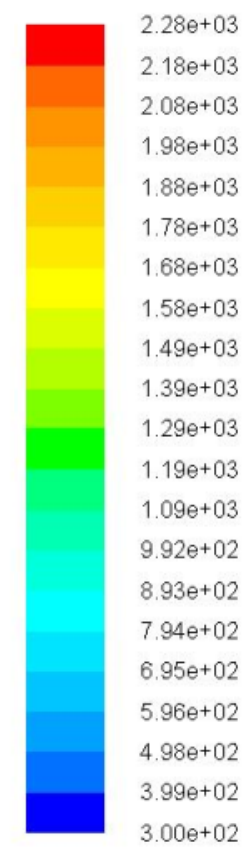

б)
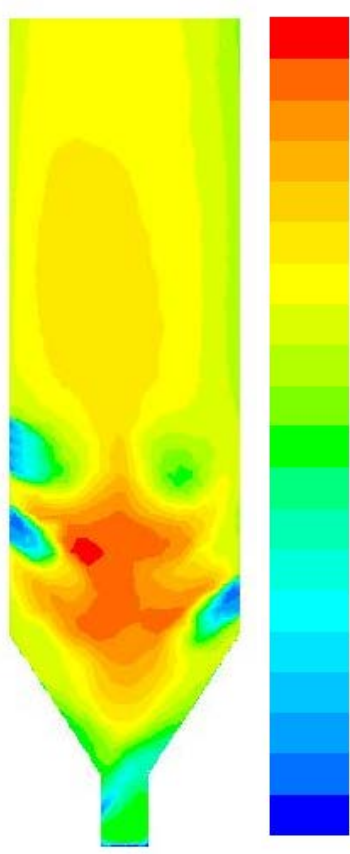

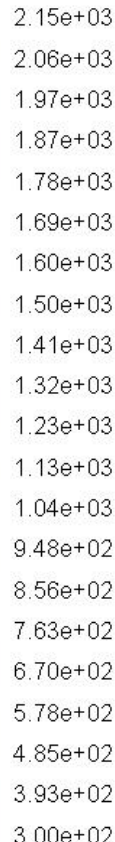

в)

Рисунок - 3. Температура газов

а) схема №1 $\alpha$ н.д = 0,57; б) схема №2, 24 горелки; в) схема №2, 16 горелок 


\section{Выводы}

1. Уменьшение количества сопл нижнего дутья и их расположение под горелками первого яруса приводит к устойчивой топочной аэродинамике.

2. Увеличение доли первичного воздуха положительно влияет на выгорание топлива.

3. Снижение доли воздуха нижнего дутья и увеличение третичного воздуха положительно влияет на выгорание топлива второго яруса горелок.

4. Сокращение числа горелок с 24 до 16 увеличивает интенсивность выгорания топлива и повышает аэродинамическую устойчивость топочного процесса.

\section{Литература:}

1. Котлы паровые большой мощности: Кат. / ОАО ВНИИАМ; ОАО НПО ЦКТИ. - М., 2009. - 116 с.

2. Тепловой расчет котельных агрегатов (нормативный метод) / Под редакцией Кузнецова Н.В. и др. М.: Энергия, 1973.

3. Перспективная технология ступенчатого сжигания угля на котле П-57 / Архипов А.М., Зройчиков Н.А., Прохоров В.Б., Каверин А.А.. Энергосбережение и Водоподготовка, 2014, №5.

4. Ansys Fluent. URL: http://www.ansys.com/Products/Fluids/ANSYS-Fluent (дата обращения: 23.06.16). 